\title{
Minimum Warpage Prediction in Plastic Injection Process using Taguchi Method and Simu- lation
}

\author{
Sigit Yoewono Martowibowo ${ }^{1}$, Reaksa Khloeun ${ }^{2}$ \\ ${ }^{1}$ Faculty of Mechanical and Aerospace Engineering, Institut Teknologi Bandung. Jalan Ganesa 10. Bandung 40132. In- \\ donesia. E-mail: sigit@ftmd.itb.ac.id \\ ${ }^{2}$ Department of Industrial and Mechanical Engineering, Institute of Technology of Cambodia, Russian Federation Bou- \\ levard, PO Box 86, Phnom Penh, Cambodia
}

\begin{abstract}
Plastic materials are used in automobile, electrical and electronic applications, agricultural utilization, household and furniture products, and medical equipments. Among various plastic manufacturing process, injection molding is one of the most commonly used and common methods applied for forming plastic products in the industry. The process requires a molten polymer being injected into a cavity of a mold, which is cooled and the product ejected from the mold. During the Plastic Injection Molding (PIM) process, various defects, such as volumetric shrinkage, warpage, weld line and sink mark can occur. This paper presents a method to minimizing warpage defect on PolyPropylene AZ564 via PIM simulation using Moldflow software. The approach was based on Taguchi method. Through the effectiveness of this proposed method, it is confirmed using simulation by Moldflow software. The effect of the process parameters on the warpage of a motorcycle number plate bracket, is studied using analysis of variance (ANOVA). From the ANOVA, the significant parameters affecting the process are holding time, holding pressure and injection pressure. The result of the Taguchi prediction shown that minimum warpage is $1.078 \mathrm{~mm}$, which is $7.14 \%$ and $9.09 \%$ different from the simulation result and experiment, respectively.
\end{abstract}

Keywords: Plastic Injection Molding, Simulation, Warpage, Design of Experiment, Moldflow

\section{Introduction}

Plastic Injection Molding (PIM) is commonly used to manufacture plastic products because of its some advantages, such as time efficiency, excellent surface and dimension of the products, and more economical. The injection molding process is divided into two stages such as plastification and injection which is characterized by four phases which are; filling, packing/holding, cooling, and ejection [1]. For the plastification stage, the solid polymer is heated until it changes from solid to the molten state to be injected into the mold cavity. Then, the molten polymer moves forward into the mold cavity under pressure through the movement of the screw which is called the injection stage. Sometimes, the PIM process can provide the product to defect. The quality of a product is based on mold design, product materials, and the injection molding parameters. The injection molding parameters are considered as one of the factors influencing in the part warpage of plastic products after demolding. In terms of the quality, warpage is the highest defect of number plate bracket plastic product. The part warpage is caused by the differential shrinkage of the injection process of number plate bracket plastic part. The differential shrinkage is based on various factors, such as; orientation effect, which can cause directional shrinkage variations. Area shrinkage is the result from packing/holding pressure and differential local crystallization, and differential cooling which causes the temperature difference between the lower and upper surfaces which provide differential shrinkage between core and cavity mold. After that, the differential shrinkage will create the bending moment that can cause warpage defect on the parts [2].

There are many researchers who have investigated the effect of injection molding parameters on the quality of the product. A study on optimization of plastic injection molding parameters for cosmetics containers concluded that the parameters most affecting the final products are temperature, holding pressure, and injection location [3]. Some researches have also conducted to develop methods of experimental design for simulation. These methods are used to obtain optimum PIM parameters to meet product requirements [4]. Oktem et al. [5] applied the Taguchi method to reduce the warpage and shrinkage issue that were associated with the variation of injection molding parameters in thin shelled plastic component products. They obtained the minimum value of warpage and volumetric shrinkage from the optimum combination of injection time, cooling time, packing/holding time, and packing/holdingpressure. Soon after, the holding pressure and holding time were revealed to be the most significant factors. Zheng et al. [6] have analyzed the influence of process parameters on warpage such as mold temperature, melting temperature, injection time, V/P switchover, holding pressure, and holding time by using the Taguchi method. Holding pressure was found to be the most influential parameter that was followed by melting temperature, holding time, $\mathrm{V} / \mathrm{P}$ switchover, injection time, and mold temperature. Kurtaran et al. [7] investigated the effects of injection molding parameters on warpage of bus ceiling lamp such as mold temperature, melting temperature, holding pressure, holding time, and cooling time through the Neural Network and Genetic Algorithm method. According to their study, it can be seen that the warpage of the bus ceiling lamp can be reduced by $46.5 \%$. Guo et al. [8] have performed a methodology that combined the design of experiment with Genetic Algorithm in order to minimize the sink marks defect of the rib by examining the rib thickness, mold temperature, melting 
temperature, and coolant temperature. As a result, the minimum value of sink marks was found. Shi et al. [9] proposed an effective methodology that used artificial neural network with parametric sampling evaluation strategy so that researchers are able to minimize the warpage defect. In their study, the mold temperature, melting temperature, injection time, holding time, holding pressure, and cooling time are considered as mold condition parameters. The result shows that the optimization method based on parametric sampling evaluation could give the minimum warpage and converge faster.

Some researchers used Moldflow software to simulate and optimize PIM process [5-7, 9-11]. Their recommendation can be offered for an optimum volumetric shrinkage, warpage, sink mark, and final product properties involving low cycle time and cost efficiency.

The purpose of this study is to create a contribution to solve the prediction problem by introducing an efficient prediction method. In this paper, the minimum warpage in PIM of PolyPropylene motorcycle number plate bracket was predicted by performing the Taguchi method combined with Moldflow simulation. Signal-to-noise $(\mathrm{S} / \mathrm{N})$ ratio was employed to find the optimum combination of injection molding parameters. Analysis of variance (ANOVA) was used to obtain the effects of significant parameters on warpage.

\section{Research Methodology}

\subsection{Plastic injection molding process}

Manufacturing plastic products by means of injection molding requires a continuous process. Injection process started as a mold which is closed. Then, the plastic powder in the hopper enters the barrel. At this point, the screw is rotating while moving backward as the plastic powder in the barrel is being heated up gradually until its melting point is reached, and then the screw moves forward which is called the feeding stroke. As the screw is moving, the molten plastic is poured into the mold, filling the cavity through the injection machine nozzle, sprue, runner, and gate. When the molten plastic is entering the cavity, a high pressure is needed to push the plastic material into the mold. Thus, injection pressure is defined as the pressure accompanying the melting of the plastic and its flow to the cavity during plastification process. As the mold cavity is being filled with plastic material, a high pressure is applied in the cavity to prevent the molten plastic from escaping the parting line. A clamping unit is also fastened and kept tight for a certain amount of time. At this point, the screw remains motionless. This process is called holding pressure process. With an injection molding process, one production cycle consists of three main phases. In the first phase, known as injection or filling step, molten plastic is fed into the mold. During the second phase, which is also called the holding step, molten plastic is added until it reaches the desired weight. The third phase, or the cooling phase, is the phase in which plastic temperature is lowered to an ambient temperature. All these phases are interrelated and affected by a number of factors such as raw material characteristics, injection molding machine condition, mold design, process parameters, and final product quality, i.e., product appearance and strength [12].

Of all the process involved in plastic molding, the cooling process is the most time-consuming and the latter is solidification process. As solidification is taking place, mold temperature is lowered by flowing coolant (normally water) into the mold. The cooling time depends on how much time is needed by the injection machine to transfer heat from the cavity to the coolant. When the product has cooled down and solidified, mold is opened by unfastening the clamping unit and pulling out the movable plate, on which the core plate is placed. At the same time, the screw moves backward as the barrel is filled with the plastic material from the hopper. Then the ejector rod in the machine pushes the ejector plate and ejector retainer plate into the mold, forcing the product out of the core. After this demolding or ejection process, the mold closes again and the cavity is filled again with molten plastic, and the entire process starts all over again.

\subsection{Design of proposed system}

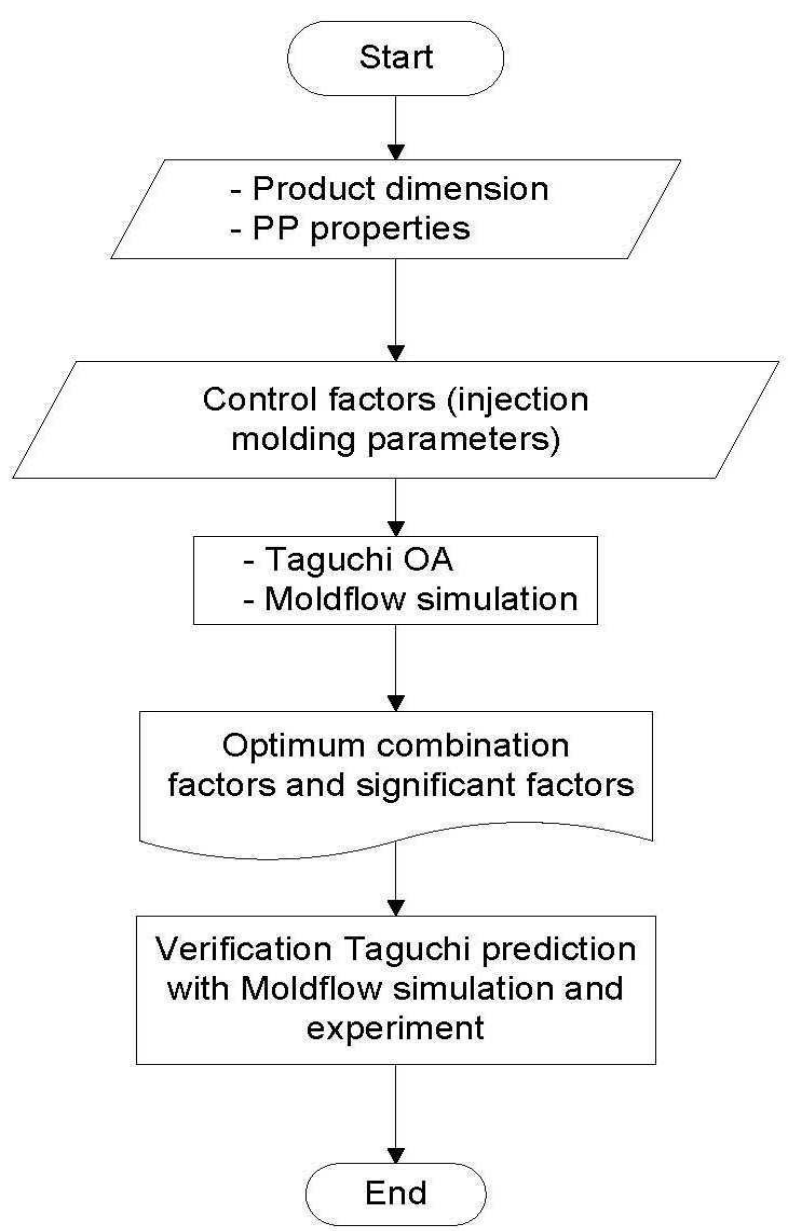

Fig. 1 Flowchart of the Proposed Methodology

To minimize the warpage defect in PIM of PolyPropylene motorcycle number plate bracket by using optimization method, the Taguchi method and Moldflow simulation were applied. The flowchart of the proposed system is shown in Fig. 1. The control variables which are considered as affecting on warpage are injection molding 
parameters. For optimization of injection molding parameters, firstly, the Taguchi method is performed to generate the number of running orthogonal arrays (OA) and by using Moldflow simulation. The optimum combination control variables is decided based on the highest $\mathrm{S} / \mathrm{N}$ ratio. The significant factors are determined by using ANOVA, and the functional correlation between control factors respons and objective function is constructed as the predicted warpage. At the end, the result of the Taguchi prediction is verified with Moldflow simulation and experiment.

\subsection{Product data}

This study is focused on plastic-based motorcycle number plate bracket, a component which its function is to hold and protect license number plate which was previously made of steel material. The product model is drawn as shown in Fig. 2 [13]. From Fig. 2, it seen that the bracket pose risks of warpage at both ends.
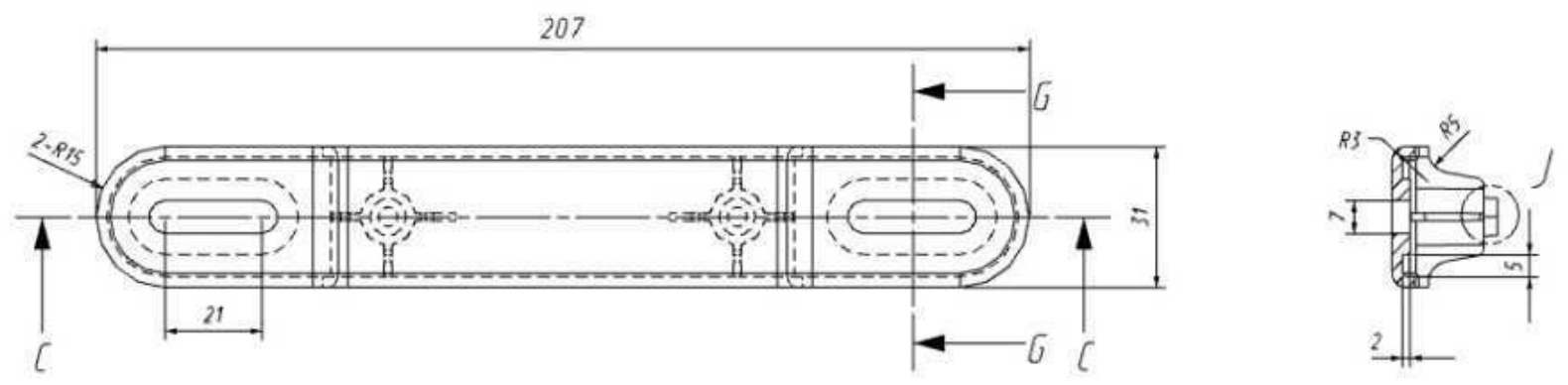

SECTION G-G
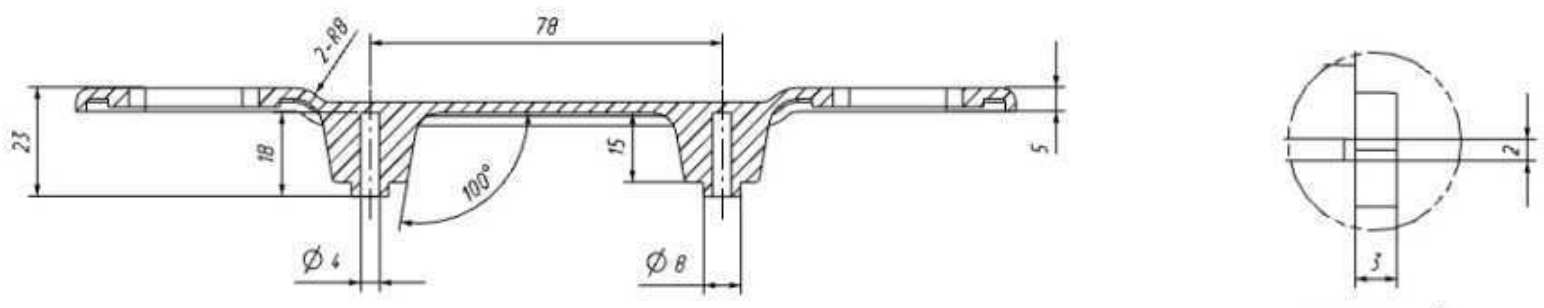

SECTION $[-[$

DETAIL $J$

Fig. 2 Number Plate Bracket Dimensions

This number plate bracket product is made of PolyPropylene thermoplastic material AZ564 from Sumitomo Chemical Co. Ltd. This type of material has good fluidity, which enables plastic products to be processed at a low melting temperature and injection pressure. Furthermore, the product is also quite resilient and has good surface quality. The AZ564 material data are shown in Tab 1.

\section{Tab. 2 Material Termoplastic}

\begin{tabular}{ll}
\hline Code & AZ564 \\
Manufacturer & Sumitomo Chemical Co. Ltd. \\
Material Structure & Crystalline \\
Melting Temperature & $180-260^{\circ} \mathrm{C}$ \\
Mold Temperature & $20-80^{\circ} \mathrm{C}$ \\
Max. Shear Stress & $0.30 \mathrm{MPa}$ \\
Melting Density & $0.78 \mathrm{~g} / \mathrm{cm}^{3}$ \\
Shrinkage Factor & $0.5 \%$ \\
\hline
\end{tabular}

After the product images had been generated, the next step was to design and manufacture the mold. All the product data had to be gathered for the designing process. Number plate brackets were produced by using four-cavity mold with two plates. Based on the designed dimensions, a detailed design of insert components for the core and cavity was made. The plastic injection machine used in this study was Hwa Chin 160SE. Injection process parameters are set by using a control panel [14].

\subsection{Taguchi method and design of experiment}

The Taguchi method has been commonly applied in engineering so that it was used to optimize the performance characteristics by setting process and design parameters. In order to optimize the quality, cost, and performance, the Taguchi method is an approach which is effective [15]. In Taguchi method, it is used OA that are more effective than the full factorial or fractional factorial design of experiment because of reducing the number of experiments [16]. However, the Taguchi method is usually performed on $\mathrm{S} / \mathrm{N}$ ratio to determine the quality characteristics in engineering design issues. Taguchi classifies parameter design problems into different categories depending on the goal of the researcher. The $\mathrm{S} / \mathrm{N}$ ratio characteristics can be devided into three catagories such as; the 'larger is the better', the 'nominal is the best', and the 'smaller is the better' [17]. In addition, the Taguchi method is used to analyze the affecting factors on quality characteristics of the product through ANOVA [18].

$\mathrm{OA}$ is the matrix of a number of rows and columns, in which each column represents a certain changeable factor or condition from another experiment. The advantage of 
orthogonal array is used to reduce the number of experiments that minimize the cost and time of experiment.

In Taguchi method, the $\mathrm{S} / \mathrm{N}$ ratio approach is used to measure the quality characteristics. Since the objective of this research is to minimize warpage defect through optimum of PIM parameters, the 'smaller the better' is performed. The formula of the 'smaller the better' can be defined as:

$$
S / N=-10 \log \left(\frac{1}{n} \sum_{i=1}^{n} y_{i}^{2}\right)
$$

Where:

n.....Number of observation,

$\mathrm{y}_{\mathrm{i}} \ldots .$. The observed data.

ANOVA is used to identify the significant injection molding process parameters or factors on warpage. They can identify that the significant injection molding process parameters based on the confidence interval of $95 \%$ which means that P-value is less than 0.05 .

\subsection{Computer simulation}

The computer simulation consists in several numerical analyses in order to perform computer modeling of plastic injection process for the selected material. In this study, Moldflow Insight 2014 has been used. In order to perform correct analysis, the input of a number of input data became necessary.

Based on the combinations of control factors, the prediction of the optimum warpage defects can be obtained by calculating the antilog of optimum $\mathrm{S} / \mathrm{N}$ ratio to obtain an optimum warpage defect value. The predicted optimum value is calculated as follows:

$$
\begin{gathered}
S / N_{o p t}=\bar{T}+\sum_{i=1}^{n}\left(\overline{C F}_{i}-\bar{T}\right) \\
y_{o p t}=\left(10^{-S / N_{o p t} / 10}\right)^{0.5}
\end{gathered}
$$

Where:

$\overline{\mathbf{C F}}_{\mathrm{i}}$..Average $\mathrm{S} / \mathrm{N}$ ratio for each level of control factors that generate optimum value,

$\overline{\mathrm{T}}$....Average $\mathrm{S} / \mathrm{N}$ ratio obtained from simulation.

\section{Optimization of Injection Molding Parameters}

\subsection{Implementation of Taguchi method}

To generate the number of running OA, Minitab 17 software was employed. The study used four factors and three levels. The design parameters and the levels chosen for the Taguchi experiments are listed in Tab 2. The present experimental design adopts Taguchi's L27 of OAs with four columns and twenty-seven rows which can be developed. These selection values were depended on the minimum and maximum recommended levels for AZ564 in the material library of Moldflow Insight software. However, the second level was calculated as the average between the first and the third level. The value of injection pressure and holding pressure were set based on the practical guide to injection molding [19].
Tab. 2 Control Factors and Their Levels

\begin{tabular}{|c|c|c|c|c|c|c|}
\hline \multirow{2}{*}{ Exp. No } & \multicolumn{4}{|c|}{ Control Factors } & \multirow{2}{*}{$\begin{array}{c}\text { Warpage } \\
(\mathrm{mm})\end{array}$} & \multirow{2}{*}{$\begin{array}{c}\mathrm{S} / \mathrm{N} \\
\text { Ratio }\end{array}$} \\
\hline & $\mathrm{A}$ & $\mathrm{B}$ & $\mathrm{C}$ & $\mathrm{D}$ & & \\
\hline 1 & 180 & 20 & 16 & 10 & 1.0466 & -0.3956 \\
\hline 2 & 180 & 24 & 18 & 12 & 1.2629 & -2.0274 \\
\hline 3 & 180 & 28 & 20 & 14 & 1.2300 & -1.7981 \\
\hline 4 & 180 & 20 & 18 & 14 & 1.0279 & -0.2390 \\
\hline 5 & 180 & 24 & 20 & 10 & 1.0451 & -0.3832 \\
\hline 6 & 180 & 28 & 16 & 12 & 1.2606 & -2.0115 \\
\hline 7 & 180 & 20 & 20 & 12 & 1.0010 & -0.0087 \\
\hline 8 & 180 & 24 & 16 & 14 & 1.5013 & -3.5293 \\
\hline 9 & 180 & 28 & 18 & 10 & 1.0331 & -0.2828 \\
\hline 10 & 220 & 24 & 20 & 14 & 1.2447 & -1.9013 \\
\hline 11 & 220 & 28 & 16 & 10 & 1.1507 & -1.2192 \\
\hline 12 & 220 & 20 & 18 & 12 & 1.1409 & -1.1450 \\
\hline 13 & 220 & 24 & 16 & 12 & 1.0286 & -0.2449 \\
\hline 14 & 220 & 28 & 18 & 14 & 1.2638 & -2.0336 \\
\hline 15 & 220 & 20 & 20 & 10 & 1.2261 & -1.7705 \\
\hline 16 & 220 & 24 & 18 & 10 & 1.1797 & -1.4354 \\
\hline 17 & 220 & 28 & 20 & 12 & 1.0010 & -0.0087 \\
\hline 18 & 220 & 20 & 16 & 14 & 1.2606 & -2.0115 \\
\hline 19 & 260 & 28 & 18 & 12 & 1.1629 & -1.3108 \\
\hline 20 & 260 & 20 & 20 & 14 & 1.1797 & -1.4354 \\
\hline 21 & 260 & 24 & 16 & 10 & 1.3057 & -2.3169 \\
\hline 22 & 260 & 28 & 20 & 10 & 1.2453 & -1.9055 \\
\hline 23 & 260 & 20 & 16 & 12 & 1.1145 & -0.9416 \\
\hline 24 & 260 & 24 & 18 & 14 & 1.0007 & -0.0061 \\
\hline 25 & 260 & 28 & 16 & 14 & 1.0456 & -0.3873 \\
\hline 26 & 260 & 20 & 18 & 10 & 1.2442 & -1.8978 \\
\hline 27 & 260 & 24 & 20 & 12 & 1.1288 & -1.0523 \\
\hline \multicolumn{5}{|c|}{ Average } & 1.1604 & -1.2922 \\
\hline
\end{tabular}

\begin{tabular}{lcccc}
\hline \multirow{2}{*}{ Control Factors } & & \multicolumn{3}{c}{ Level } \\
\cline { 3 - 5 } & & 1 & 2 & 3 \\
\hline A-Melting Temperature & $\mathrm{T}_{\mathrm{M}}$ & 180 & 220 & 260 \\
B-Injection Pressure & $\mathrm{P}_{\text {inj }}$ & 20 & 24 & 28 \\
C-Holding Pressure & $\mathrm{P}_{\text {hold }}$ & 16 & 18 & 20 \\
D-Holding Time & $\mathrm{t}_{\text {hold }}$ & 10 & 12 & 14 \\
\hline
\end{tabular}

Tab. 3 Simulation Results for Warpage

After the value of each parameter is divided into three levels, the value was inserted into the OA L27 with the combination of each level code. However, the results of these combination control factors are warpage which generates by Moldflow simulation. The combined values of the process parameter and results can be seen in Tab 3.This study aims to minimize warpage. Therefore, constituting 'the smaller the better' principle of the $\mathrm{S} / \mathrm{N}$ ratio for warpage. The data measured in this study are; melting temperature (A), injection pressure (B), holding pressure (C) and holding time (D). Warpage is obtained from Moldflow simulation. The combined values of the process parameter and results can be seen in Tab 3 . Combination of parameters was generated using Taguchi's L27 of OA (Table 3). The results of Moldflow simulation for warpage and the corresponding $\mathrm{S} / \mathrm{N}$ ratios 
calculated according to Eq. (1) are shown in Tab 3. The 1st run order with $\mathrm{TM}=180{ }^{\circ} \mathrm{C}$, Pinj $=20 \mathrm{MPa}$, Phold $=$ $16 \mathrm{MPa}$ and thold $=10 \mathrm{~s}$ yielded warpage response of $1.0466 \mathrm{~mm}$. Simulation continued until the 27 th run order. All the resulting responses were recorded.

After conducting the $\mathrm{OA} \mathrm{L} \mathrm{L}_{27}$, the results were analyzed by performing the $\mathrm{S} / \mathrm{N}$ ratio. The $\mathrm{S} / \mathrm{N}$ ratios for each parameter at different levels for warpage are plotted in Fig. 3. The optimum setting for warpage yielding the minimum values is shown in Fig. 3. These points for warpage defect are as follows: factor $\mathrm{A}$ was level 1 (melting temperature of $180^{\circ} \mathrm{C}$ ), factor $\mathrm{B}$ was level 1 (injection pressure of $20 \mathrm{MPa}$ ), factor $\mathrm{C}$ was level 3 (holding pressure of $20 \mathrm{MPa}$ ), and factor D was level 2 (holding time of 12s).

Applying ANOVA, the effects of each input parameter on warpage can be determined. As shown in Fig. 3 and Tab 4, the factor that most significantly affected the warpage was holding time, as evident from the value in the chart (Fig. 3) and the largest contribution of 50.89\% (Tab 4). In conclusion, holding time at $12 \mathrm{~s}$, will result a small warpage. The following factor affected warpage are holding pressure at $23.68 \%$ and injection pressure at $22.59 \%$. Then, the effect of melting temperature was insignificant.

\section{Main Effects Plot for SN ratios}

Data Means

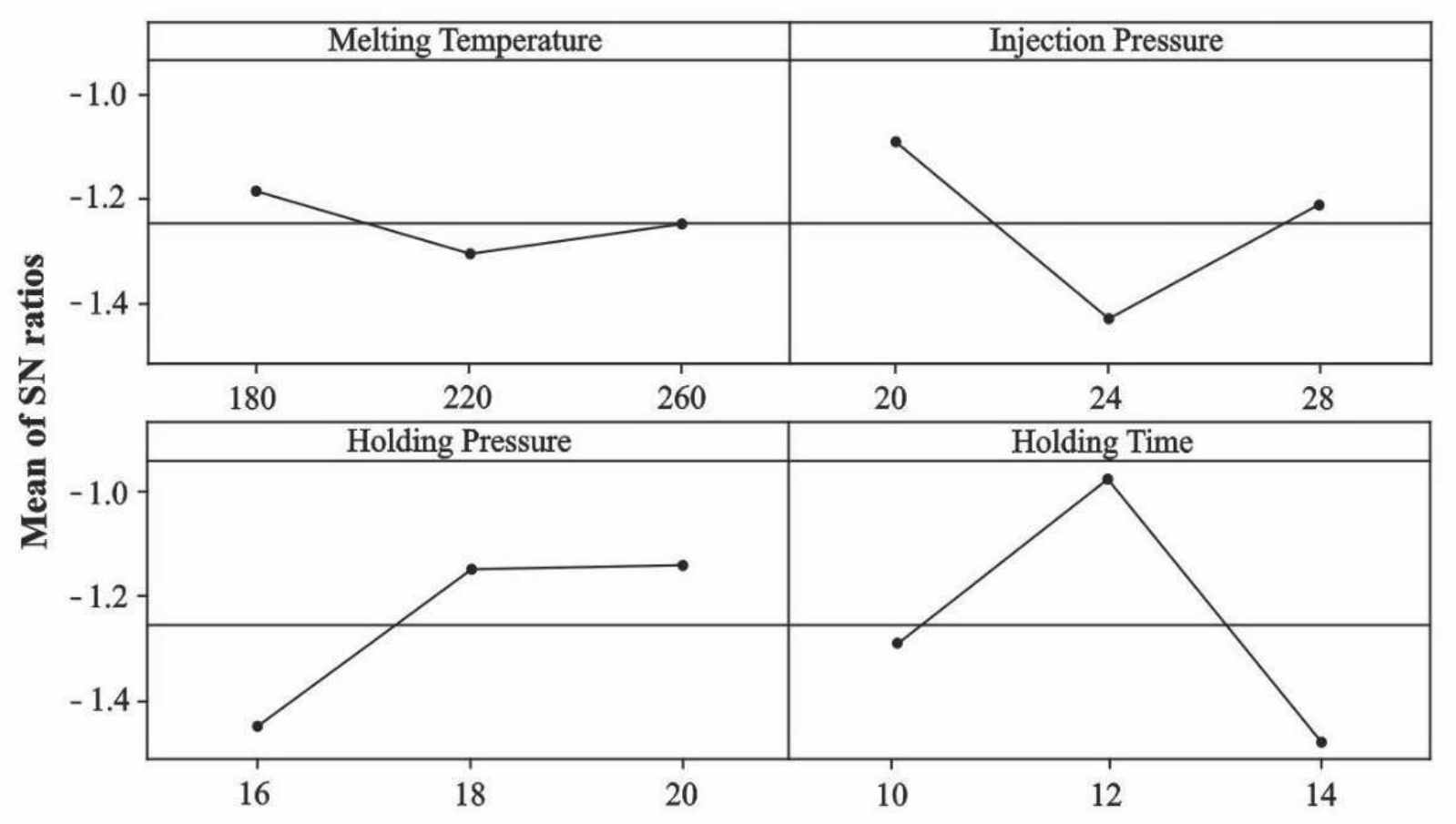

Signal-to-noise: Smaller is better

Fig. 3 S/N Ratio Effects on Warpage

Tab. 4 ANOVA Result for Warpage

\begin{tabular}{cccccc} 
Control Factors & $\begin{array}{c}\text { Degree of Fre- } \\
\text { edom (DF) }\end{array}$ & $\begin{array}{c}\text { Sum of Square } \\
\text { (SS) }\end{array}$ & Variance (V) & $\begin{array}{c}\text { Variance } \\
\text { Ratio } \\
(\mathrm{F})\end{array}$ & \% Contribution \\
\hline A & 2 & 0.06662 & 0.03331 & 0.03285 & 2.84 \\
B & 2 & 0.53003 & 0.26501 & 0.26137 & 22.59 \\
C & 2 & 0.55571 & 0.27786 & 0.27403 & 23.68 \\
D & 2 & 1.19411 & 0.59705 & 0.58884 & 50.89 \\
error & 18 & 18.25110 & & & 100.00 \\
Total & 26 & 20.59757 & & & \\
\hline
\end{tabular}

\section{Results and Discussion}

In this study, prediction of warpage was conducted using Taguchi method and Moldflow simulation. The prediction of warpage using an optimum combination of parameters was calculated using Eq. (2) and (3). The combination of parameters resulting from the Taguchi prediction was used as inputs for the Moldflow simulation. The results of the prediction, simulation and experiment are presented in Tab 5. 
Tab. 5 Confirmation Results between Taguchi Prediction-Moldflow Simulation-Experiment

\begin{tabular}{cccc|ccc}
\multicolumn{3}{c|}{$\begin{array}{c}\text { Process Parame- } \\
\text { ters }\end{array}$} & \multicolumn{3}{c}{ Warpage (mm) } \\
\hline A & B & C & D & $\begin{array}{l}\text { Pre- } \\
\text { diction }\end{array}$ & $\begin{array}{c}\text { Simula- } \\
\text { tion }\end{array}$ & $\begin{array}{c}\text { Experi- } \\
\text { ment }\end{array}$ \\
\hline 180 & 20 & 20 & 12 & 1.078 & $\begin{array}{c}1.001 \\
(7.14 \%)\end{array}$ & $\begin{array}{c}0.980 \\
(9.09 \%)\end{array}$ \\
\hline
\end{tabular}

Table 5 shows the warpage results obtained from the Taguchi prediction, Moldflow simulation and confirmation experiment using the optimal process parameters. It reveals the warpage obtained from simulation and experiment differing $7.14 \%$ and $9.09 \%$ from the Taguchi prediction.

The results of $\mathrm{S} / \mathrm{N}$ ratios and ANOVA indicated that the holding time had the most significant effect on the warpage. The holding pressure and injection pressure had the second and the third influences. These results seem to be in contrast with the results of $[5,15]$, which indicates holding pressure as the most significant factor. However, the results of $[20,21]$ seemed to be approved with those obtained in this study.

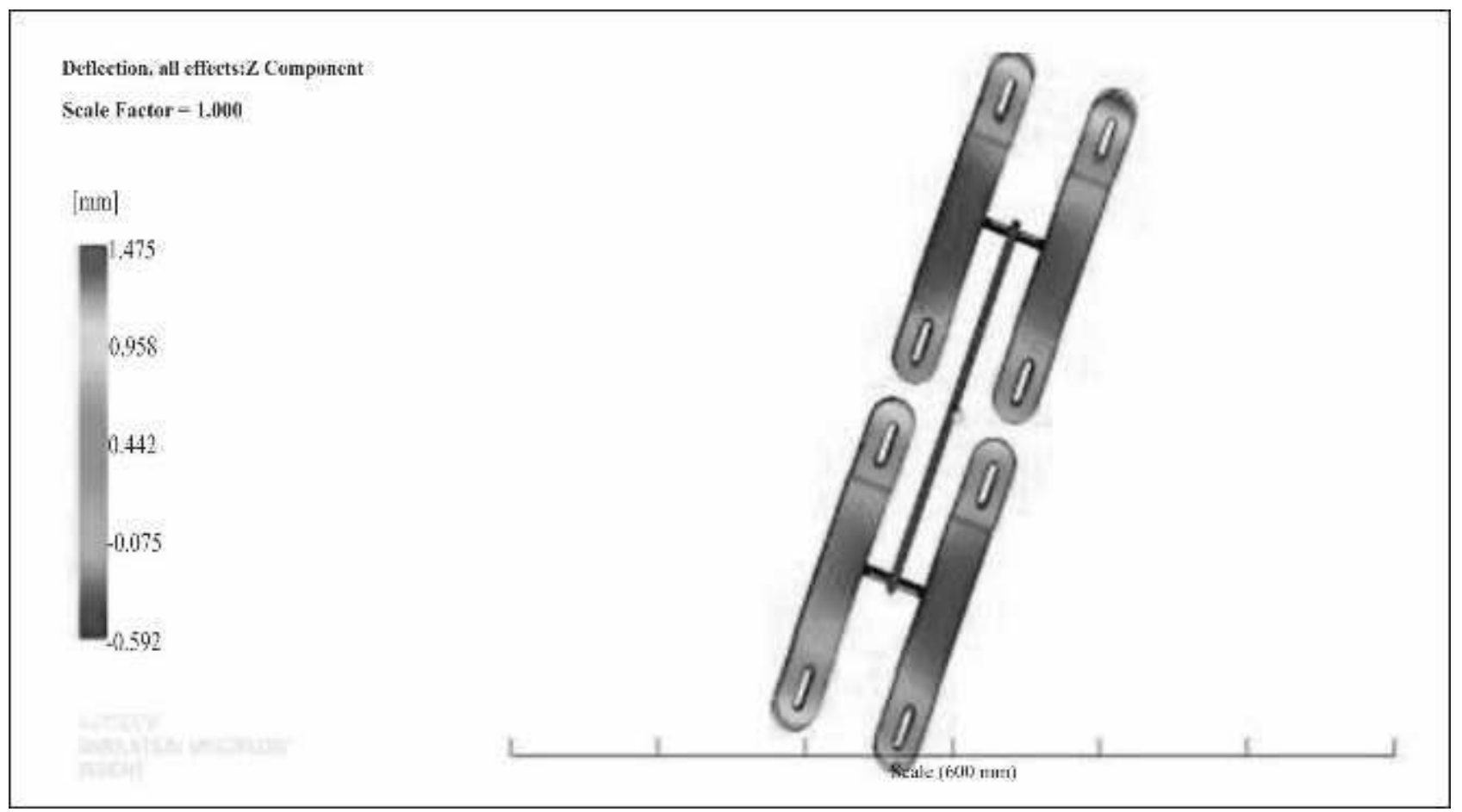

a) Using Non-Optimized Parameters

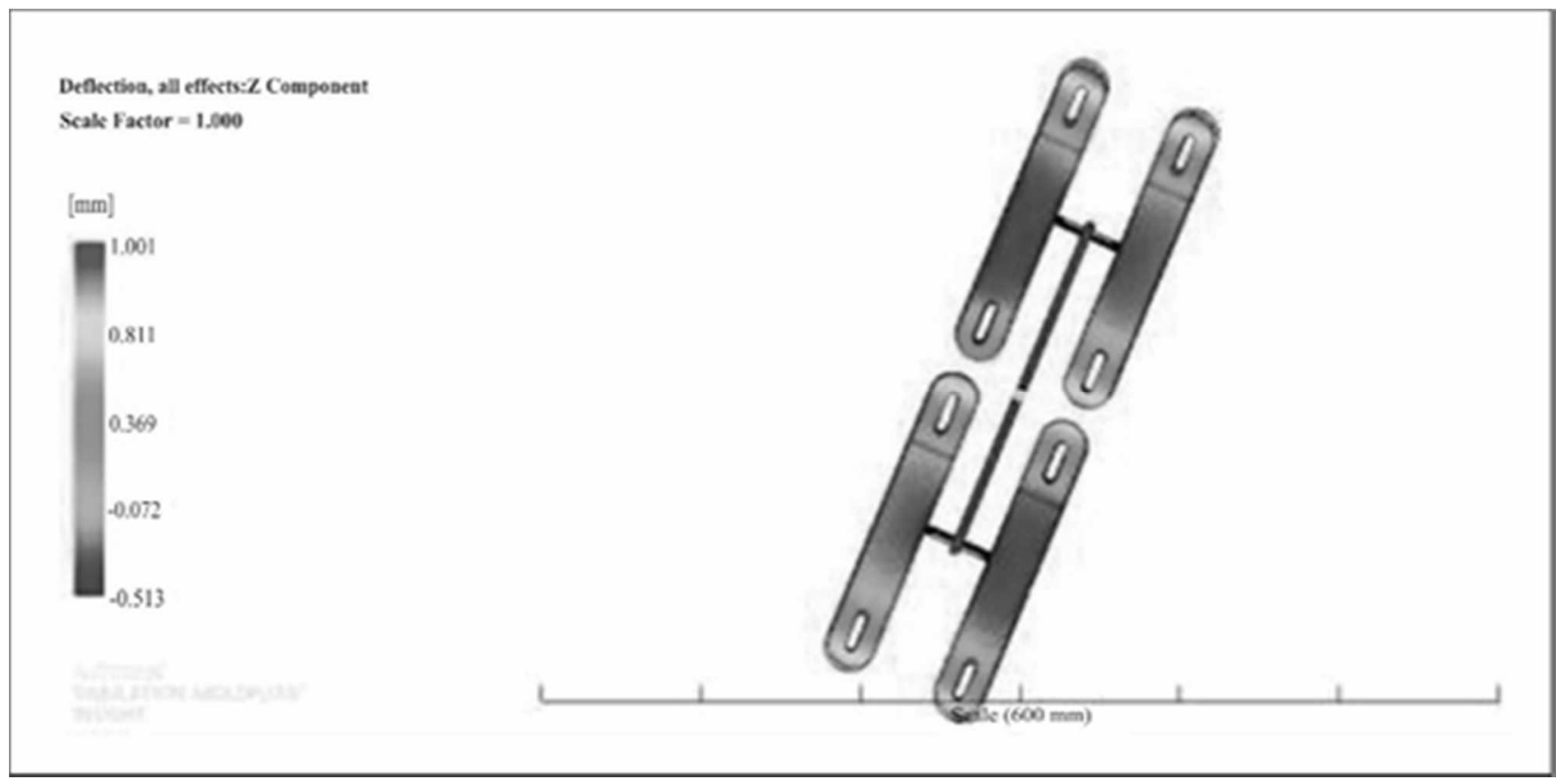

b) Using Optimum Parameters

Fig. 4 Simulation Results of Warpage 
Figure 4 shows the result of Moldflow simulation using non-optimized and optimized process parameters. Figure 4 (a) indicates that warpage still occurred at the end of the product. After process parameters were optimized, warpage is decreased $32.14 \%$ and small defects were still found in on certain parts (Fig. 4 (b)). These results are proved with experimental results shown in Fig. 5 .

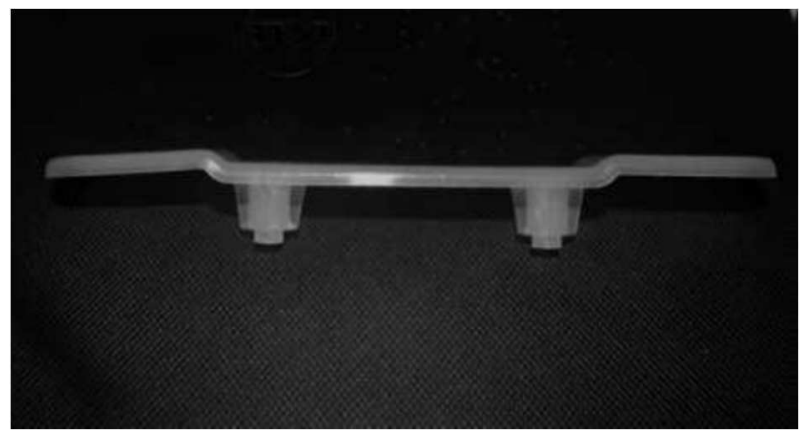

a) Using Non-Optimized Parameters

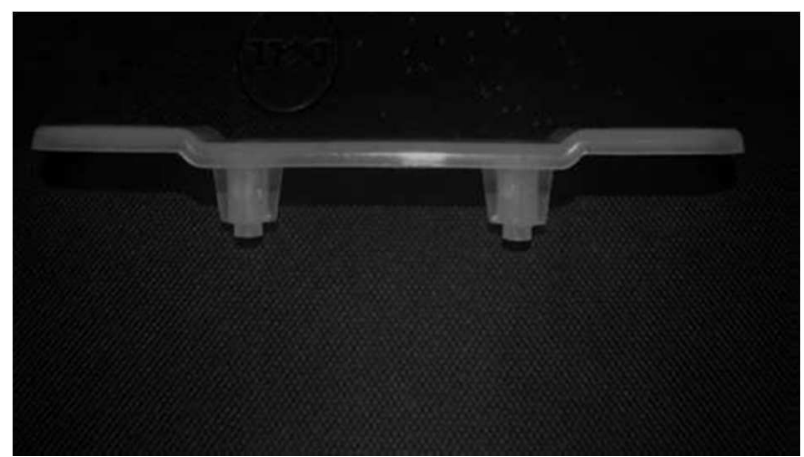

b) Using Optimum Parameters

Fig. 5 Experimental Results of Warpage

\section{Conclusions}

This study was focused on the application of Taguchi method and Moldflow simulation to predict the optimum combination of injection molding parameters and significant effect on warpage defect of AZ564 number plate bracket in PIM. Based on the Taguchi method and Moldflow simulation, the following results are drawn:

1. According to the calculation of ANOVA, it can be shown that holding time is the most influential factor with a percentage value of $50.89 \%$ on warpage which was followed by holding pressure of $23.68 \%$ and injection pressure of $22.59 \%$. The effect of melting temperature was insignificant. The optimum combination of parameters is melting temperature of $180^{\circ} \mathrm{C}$, injection pressure of $20 \mathrm{MPa}$, holding pressure of $20 \mathrm{MPa}$ and holding time of $12 \mathrm{~s}$. The Taguchi prediction for warpage was calculated and the result is $1.078 \mathrm{~mm}$.

2. From the result of verification using Moldflow simulation and experiment at optimum combination of parameters, the warpage defect is 1.001 $\mathrm{mm}$ and 0.980 , respectively. The difference between the minimum value from Taguchi prediction and simulation result and experiment are
$0.077 \mathrm{~mm}(7.14 \%)$ and $0.098 \mathrm{~mm}(9.09 \%)$, respectively. Hence, the error of warpage prediction can be acceptable because Taguchi prediction is relatively closed to simulation result and experiment.

It is concluded that the prediction of warpage in PIM of PolyPropylene motorcycle number plate bracket using Taguchi method combined with Moldflow simulation is effective to shorten the time consumed for running the trial-and-error, and is also leading to eliminate the possibility of product defects.

\section{Acknowledgement}

The authors would like to express their utmost gratitude to the Ministry of Research, Technology and Higher Education of the Republic of Indonesia, for their financial support. The authors also thank to the Politeknik Manufaktur Astra, Indonesia, for providing laboratory facilities.

\section{References}

[1] ZHENG, R., TANNER, R.I., FAN, X.J. (2011). Injection molding: integration of theory and modeling methods. Springer-Verlag, Berlin.

[2] HUANG, M.C., TAI, C.C. (2001). The effective factors in the warpage problem of an injectionmolded part with a thin shell feature. In: Journal of Materials Processing Technology, Vol. 110, No. 1, pp. 1-9. Elsevier BV, Netherlands.

[3] CHEN, W.S., YU, F.J., WU, S.H. (2011). A robust design for plastic injection molding applying Taguchi method and PCA. In: Journal of Science and Engineering Technology, Vol. 7, No. 2, pp.1-8. Taiwan.

[4] ANDRISANO, A.O., GHERARDINI, F., LEALI, F., PELLICCIARI, M., VERGNANO, A. (2011). Design of simulation experiments method for injection molding process optimization. In: Proceeding of the International Conference on Innovative Methods in Product Design, 15-17 June 2011, pp. 476-486, Venice, Italy.

[5] OKTEM, H., ERZURUMLU, T., UZMAN, I. (2007). Application of Taguchi optimization technique in determining plastic injection molding process parameters for a thin shell part. In: Materials and Design, Vol. 28, No. 4, pp. 1271-1278. Elsevier BV, Netherlands.

[6] ZHENG, G., GUO, W., WANG, Q., GUO, X. (2015). Influence of processing parameters on warpage according to the Taguchi experiment. In: Journal of Mechanical Science and Technology, Vol. 29, No. 10, pp. 4153-4158. Springer-Verlag, Germany.

[7] KURTARAN, H., OZCELIK, B., ERZURUMLU, T. (2005). Warpage optimization of a bus ceiling lamp base using neural network model and genetic 
algorithm. In: Journal of Materials Processing Technology, Vol. 169, No. 2, pp. 314-319. Elsevier BV, Netherlands.

[8] GUO, W., HUA, L., MAO, H. (2014). Minimization of sink mark depth in injection-molded thermoplastic through design of experiments and genetic algorithm. In: The International Journal of Advanced Manufacturing Technology, Vol. 72, No. 1-4, pp. 365-375. Springer-Verlag, Germany.

[9] SHI, H., XIE, S., WANG, X. (2013). A warpage optimization method for injection molding using artificial neural network with parametric sampling evaluation strategy. In: The International Journal of Advanced Manufacturing Technology, Vol. 65, No. 1-4, pp. 343-353. Springer-Verlag, Germany.

[10] FARSHI, B., GHESHMI, S., MIANDOABCHI, E. (2011). Optimization of injection molding process parameters using sequential simplex algorithm. In: Materials and Design, Vol. 32, No. 1, pp. 414-423. Elsevier BV, Netherlands.

[11] MONKA, P., HLOCH, S., ANDREJ, A., SOMSAK, M., MURGAS, F. (2016). Simulation tools used at the injection mould design. In: $M a-$ nufacturing Technology, Vol. 16, No. 3, pp. 561569. Institute of Technology and Production Management University of J.E. Purkyne, Czech Republic.

[12] MARTOWIBOWO, S.Y., KASWADI, A. (2017). Optimization and Simulation of Plastic Injection Process using Genetic Algorithm and Moldflow. In: Chinese Journal of Mechanical Engineering, Vol. 30, No. 2, pp. 398-406. Springer-Verlag, Germany.

[13] MARTOWIBOWO, S.Y., KASWADI, A., LUBIS, G.S. (2017). Application of Taguchi method-Moldflow-particle swarm optimization for plastic injection process parameters optimization. In: Manufacturing Technology, Vol. 17, No. 4, pp. 512-519. Institute of Technology and Production Management University of J.E. Purkyne. Czech Republic.
[14] Hwa Chin Plastic Injection Machine. Retrieved February 12, 2016, from http://www.hwachin.com.

[15] OZCELIK, B., ERZURUMLU, T. (2006). Comparison of the warpage optimization in the plastic injection molding using ANOVA, neural network model and genetic algorithm. In: Journal of Materials Processing Technology, Vol. 171, No. 3, pp. 437-445. Elsevier BV, Netherlands.

[16] JOSE, S., FANGUEIRO, J.F., SMITHA, J., CINU, T.A., CHACKO, A.J., PREMALETHA, K., SOUTO, E.B. (2012). Cross-linked chitosan microspheres for oral delivery of insulin: Taguchi design and in vivo testing. In: Colloids and Surfaces B: Biointerfaces, Vol. 92, pp. 175-179. Elsevier BV, Netherlands.

[17] TAGUCHI, G. (1990). Introduction to quality engineering. Asian Productivity Organization, Tokyo.

[18] TSAI, K.M., HSIEH, C.Y., LO, W.C. (2009). A study of the effects of process parameters for injection molding on surface quality of optical lenses. In: Journal of Materials Processing Technology, Vol. 209, No. 7, pp. 3469-3477. Elsevier BV, Netherlands.

[19] GOODSHIP, V. (Ed.) (2004). Arburg-Practical guide to injection moulding. Smithers Rapra Press, Shawbury.

[20] CHEN, W.C., KURNIAWAN, D. (2014). Process parameters optimization for multiple quality characteristics in plastic injection molding using Taguchi method, BPNN, GA, and hybrid PSO-GA. In: International Journal of Precision Engineering and Manufacturing, Vol. 15, No. 8, pp. 15831593.

[21] SUDSAWAT, S., SRISEUBSAI, W. (2018). Warpage reduction through optimized process parameters and annealed process of injection-molded plastic parts. In: Journal of Mechanical Science and Technology, Vol. 32, No. 10, pp. 4787-4799. 